\title{
Sismoestratigrafia da porção sul da Bacia do Recôncavo e norte da Bacia de Camamu
}

Daniel Bono R. Vilas Boas*, GETA/IGEO/UFBA; Paulo Augusto Vidigal D. Souza, GETA/IGEO/UFBA; Edric B. Troccoli, GETA/IGEO/UFBA; Michael Holz, GETA/IGEO/UFBA

Copyright 2016, SBGf - Sociedade Brasileira de Geofísica

Este texto foi preparado para a apresentação no VII Simpósio Brasileiro de Geofísica, Ouro Preto, 25 a 27 de outubro de 2016. Seu conteúdo foi revisado pelo Comitê Técnico do VII SimBGf, mas não necessariamente representa a opinião da SBGf ou de seus associados. E proibida a reprodução total ou parcial deste material para propósitos comerciais sem prévia autorização da SBGf.

\section{Abstract}

This work consists in seismic interpretation of poststack data of the area abridged by southern Recôncavo and northern Camamu basins, aided by the interpretation of well logs; including mapping of structural features (i.e., basement top and main fault systems) and the key stratigraphic surfaces (i.e., synrift and post-rift unconformities, as well as internal unconformities of the rift supersequence), resulting in a high-resolution stratigraphic correlation between the basins.

\section{Introdução}

As bacias do Recôncavo e de Camamu apresentam comprovado potencial petrolífero associado às suas seções rifte, mas a continuidade estratal entre as bacias nunca foi adequadamente estudada. $O$ presente trabalho tem como principal objetivo a interpretação sísmica da região do contato entre as bacias do Recôncavo e de Camamu, correlacionando-se os depósitos entre as bacias, especialmente em suas seções sin-rifte. Para tanto, seguiu-se os princípios da estratigrafia de sequências aplicada a bacias rifte, inicialmente preconizada por Prosser (1993), que elaborou uma adaptação ao modelo da estratigrafia de sequências clássico, ao levar em consideração que o principal mecanismo controlador da acomodação é o tectonismo associado ao rifteamento, gerando padrões de progradação e retrogradação diferentes em comparação com o modelo da estratigrafia de margem passiva. $O$ modelo usado no presente trabalho (apud Holz et al., 2014), com seus tratos de sistemas tectônicos e superfícies estratigráficas chaves, é mostrado na Fig. 1.

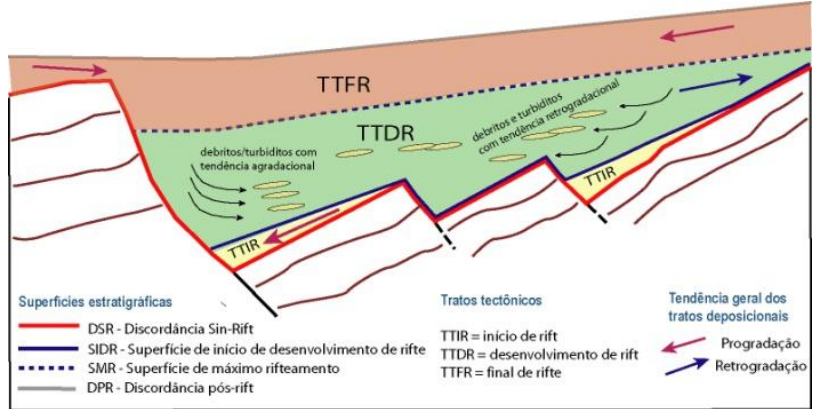

Figura 1 - Modelo estratigráfico para um sistema de meiográben de bacia rifte, modificado de Holz et al. (2014). Notar as superfícies-chaves e os três tratos deposicionais.

\section{Área de Estudo / Banco de Dados}

Os dados sísmicos e de poços disponíveis para o estudo integram o banco de dados do projeto de P\&D GP-03 financiado pela empresa GEOPARK e denominado Projeto RECAMU (Análise geológica comparativa da fase rifte da Bacia de Camamu e da Bacia do Recôncavo). Foram utilizados 140 linhas sísmicas pós-empilhadas e dados de 27 poços, todos eles sobre a área que compõe a porção sul da Bacia do Recôncavo e norte da Bacia de Camamu, dispostos como mostra o mapa da Figura 2.

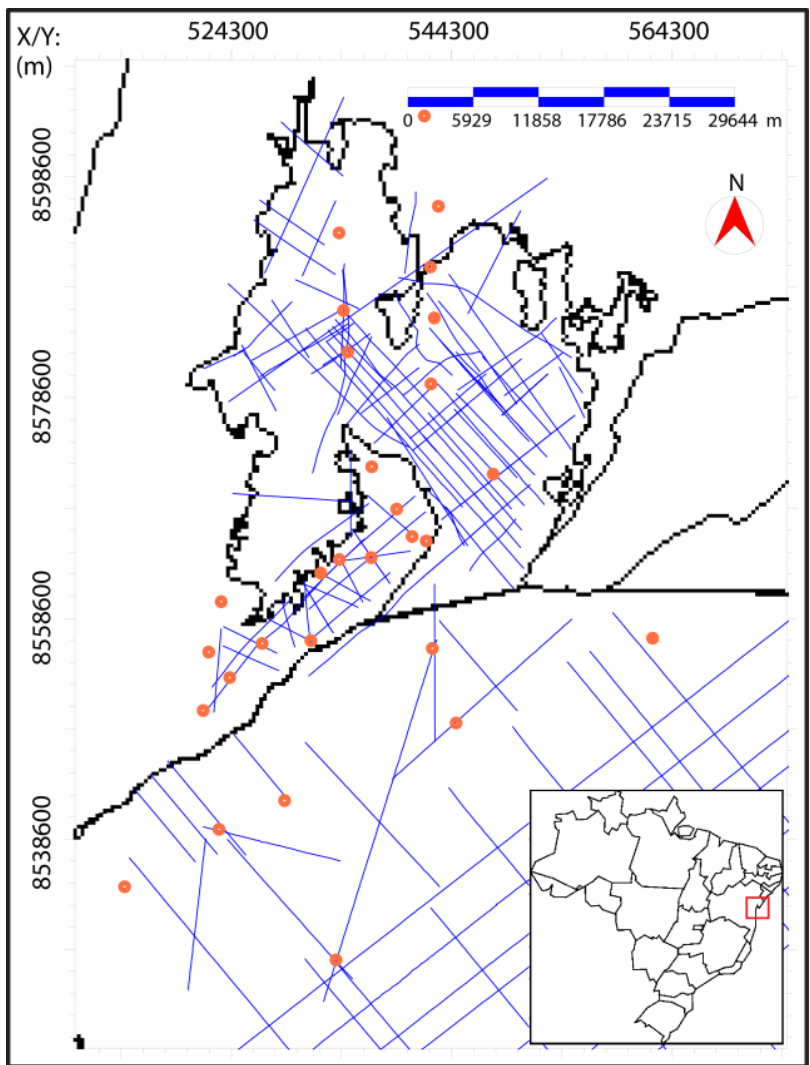

Figura 2 - Linhas sísmicas (em azul) e poços (em vermelho) disponíveis, inseridos na área de estudo.

\section{Metodologia}

Desenvolveu-se as etapas convencionais de uma interpretação sismoestratigráfica, tendo sido utilizado principalmente o software de interpretação sísmica IHS Kingdom. Os perfis geofísicos de poços, especialmente os de raios gama, foram interpretados sob a óptica da estratigrafia de sequências aplicada a bacias rifte. 
A interpretação sismoestratigráfica foi auxiliada pela análise de atributos sísmicos do traço complexo, como amplitude, fase e frequência instantâneas, os quais foram úteis na identificação de terminações estratais e continuidades de refletores. O TecVA (Técnica Volume de Amplitudes, ou pseudorelief) foi fundamental no mapeamento estrutural do topo do embasamento e das principais falhas nas seções. Os atributos citados podem ser visualizados nas seções da Figura 3.

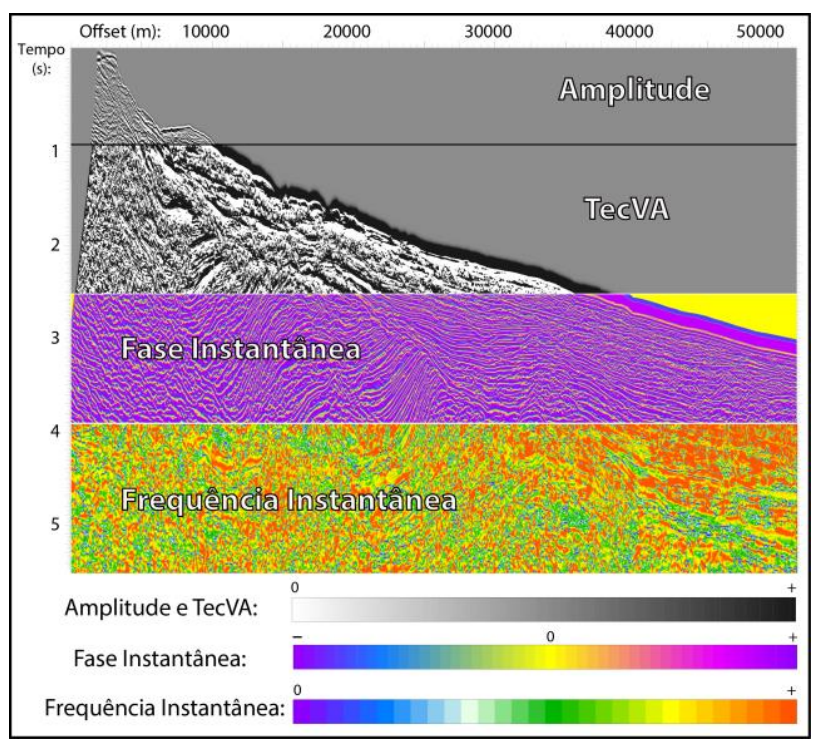

Figura 3 - Atributos sísmicos calculados e plotados em seção no software IHS Kingdom (amplitude, TecVA, fase e frequência instantâneas).

Para correlação entre os dados sísmicos e de poços, foram gerados sismogramas sintéticos a partir das curvas de densidade e sônico. Um exemplo de amarração sísmica-poço pode ser visualizado através do painel de correlação do traço sintético com os traços registrados, e do posicionamento resultante do poço na seção, exibidos na Figura 4.

Dados culturais retirados da literatura das bacias estudadas foram também úteis na interpretação, especialmente mapas gravimétricos e estruturais dos trabalhos de Ferreira et al. (2009) e Destro et al. (2003). As superfícies demarcadas na interpretação possibilitaram a confecção de modelos geológicos, ilustrando a disposição das camadas em subsuperfície da região estudada, esquematizando a correlação entre os depósitos das bacias.

\section{Análise sismoestratigráfica}

Foram interpretadas sequências de terceira ordem, onde os depósitos das fases sinéclise, pré-rifte e sin-rifte foram, correlacionáveis cronoestratigraficamente entre as bacias do Recôncavo e de Camamu. Feições estruturais como a Falha da Barra atravessam a seção rifte entre as bacias; contudo, não as diferencia em seu caráter

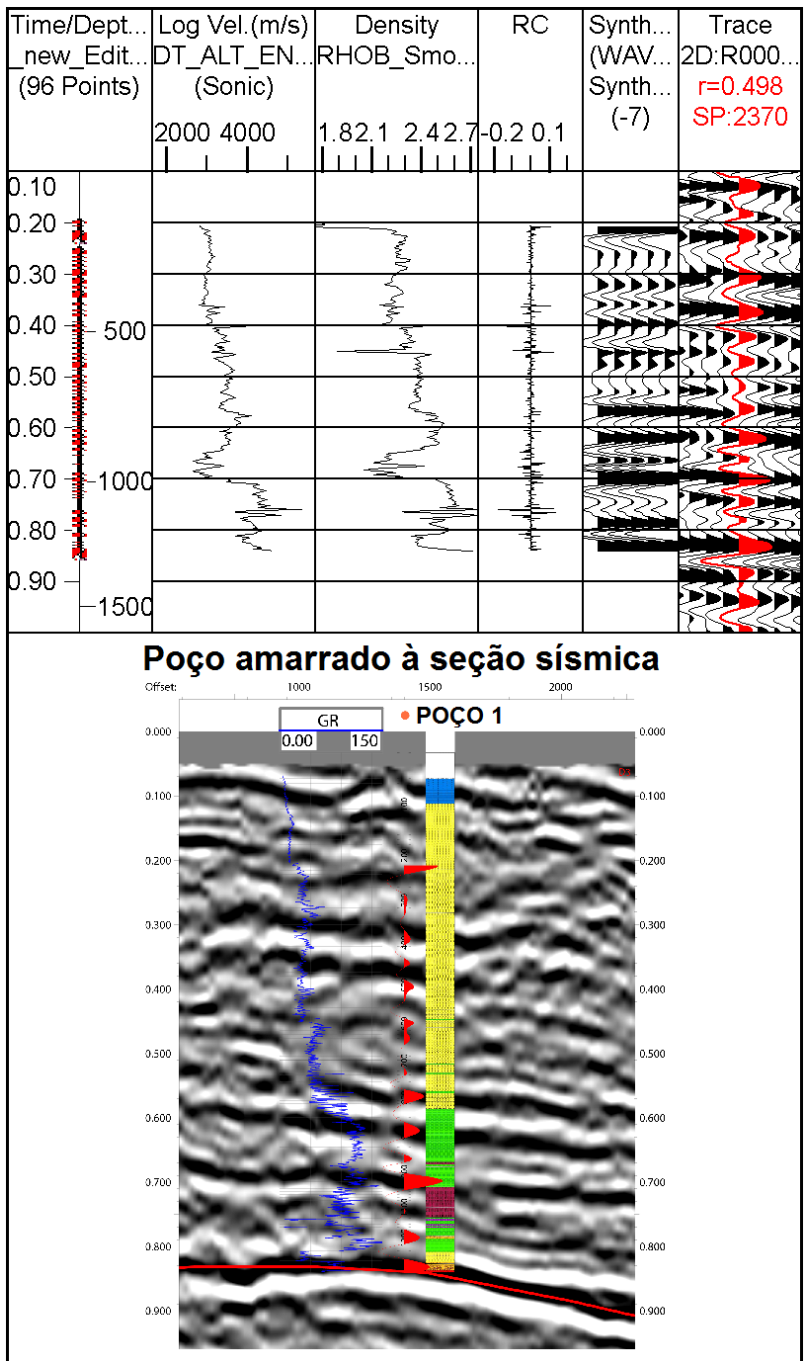

Figura 4 - Painel de correlação sísmica-poço, e a amarração resultante na seção sísmica. Notar a excelente correspondência entre traços sísmicos e camadas-guias no poço.

genético. Um resumo da interpretação realizada pode ser visualizado através da correlação com a carta de Silva et al. (2007) para a Bacia do Recôncavo (Figura 5).

Os primeiros depósitos interpretados, representam as fases sinéclise e pré-rifte das bacias, apresentadas na seção por um padrão de refletores plano-paralelos com boa continuidade, chamadas de Sequência A, limitadas na base pelo embasamento (EMB) e no topo pela discordância sin-rifte (DSR). A sequência assume espessuras sísmicas em torno de $600 \mathrm{~ms}$. A análise dos dados de poços foi fundamental na determinação da DSR, marcada no topo do padrão caixa e de baixo valor da curva de raios gama, correlato com a Formação Sergi, segundo a litoestratigrafia.

Dentro da supersequência rifte das bacias, foram mapeadas duas discordâncias, diferenciando o rifte em três sequências, chamadas de Sequências B1, B2 e B3. 
O padrão de amplitudes é variável ao longo do rifte, apresentando uma característica predominantemente progradacional nos seus primeiros depósitos, principalmente em suas porções proximais; e posteriormente um padrão plano-paralelo de baixa amplitude e continuidade, especialmente indo em direção aos depocentros.

A Sequência B1 representa os primeiros depósitos da fase sin-rifte (sobreposto à DSR), originados em um ambiente lacustre inicial, predominantemente raso. Sismicamente apresentam refletores de alta amplitude e continuidade, com espessuras sísmicas em torno de 100 $\mathrm{ms}$, que podem aumentar em direção às regiões mais profundas, indicando o contexto rifte ao qual a sequência foi formada.

A discordância D1 limita as sequências B1 e B2, onde a última mostra um padrão predominantemente retrogradacional, com uma sismofácies de baixas amplitude e continuidade, apresentando uma espessura sísmica bem variável, de 300 ms a 800 ms.

Interno à Sequência B2 foi encontrado uma superfície de downlap, que, seguindo o modelo da estratigrafia de sequências de bacias rifte (Figura 1), representa o momento de maior criação de espaço de acomodação da sequência, sendo então chamada de Superfície de Máximo Rifteamento (SMR) da Sequência B2. Os depósitos dentro da sequência sotopostos à SMR, constituem o Trato de Sistemas Tectônico de Desenvolvimento de Rifte (TTDR), e sobrepostos à essa superfície representam o Trato Tectônico Final de Rifte (TTFR). O TTDR tem um padrão retrogradacional, indicando aumento do tectonismo e expansão do sistema lacustre; enquanto que o TTFR constitui um padrão predominantemente progradacional de um aumento da influência dos sistemas fluviais e deltaicos, sob diminuição da atividade tectônica. A interpretação estratigráfica dos poços foi fundamental na determinação da SMR (indicada muitas vezes por máximos locais da curva de raios gama, e passagem de um padrão retrogradacional para progradacional), e consequentemente na delimitação dos tratos de sistemas da seção rifte.

Limitada pelas discordâncias D2 e DPR (discordância pós-rifte), a Sequência B3 apresenta os últimos depósitos da seção rifte das bacias, apresentando sismofácies semelhante ao da Sequência B2, e também indicada por uma grande variação de espessura, que possui os maiores valores em direção à Camamu. Algumas linhas que compõe principalmente a área da Bacia de Camamu, permitem identificar mais uma discordância acima da D2, e anterior à DPR, portanto, podem segmentar ainda mais os depósitos rifte, contudo, tal discordância é de menor hierarquia e se apresenta de maneira restrita em apenas algumas seções.

Indicada por uma série de truncamentos subjacentes, a discordância pós-rifte limita os depósitos rifte das porções pós-rifte das bacias, sendo a última interpretada como Sequência C, ao qual representa a primeira grande mudança nos depósitos entre as bacias do Recôncavo e de Camamu. Na região do Recôncavo, a última sequência apresenta uma sismofácies predominantemente tabular, com refletores planoparalelos que variam em termos de amplitude a depender da seção analisada, considerando que os depósitos se encontram muito rasos, altamente submetidos à Zona de Baixa Velocidade (ZBV). Nas regiões offshore da Bacia de Camamu, a Sequência $C$ já é marcada por uma sismofácies de amplitude mais baixa, levemente caótica, com grande diferença angular entre os depósitos rifte, sendo limitada ao topo pela discordância D5.

Apenas existente nas porções marinhas da Bacia de Camamu, os depósitos drifte foram segmentados em cinco sequências sedimentares, limitadas pelas discordâncias DPR, D5, D6, D7, D8 E D9, como ilustrado na seção composta da Figura 7.

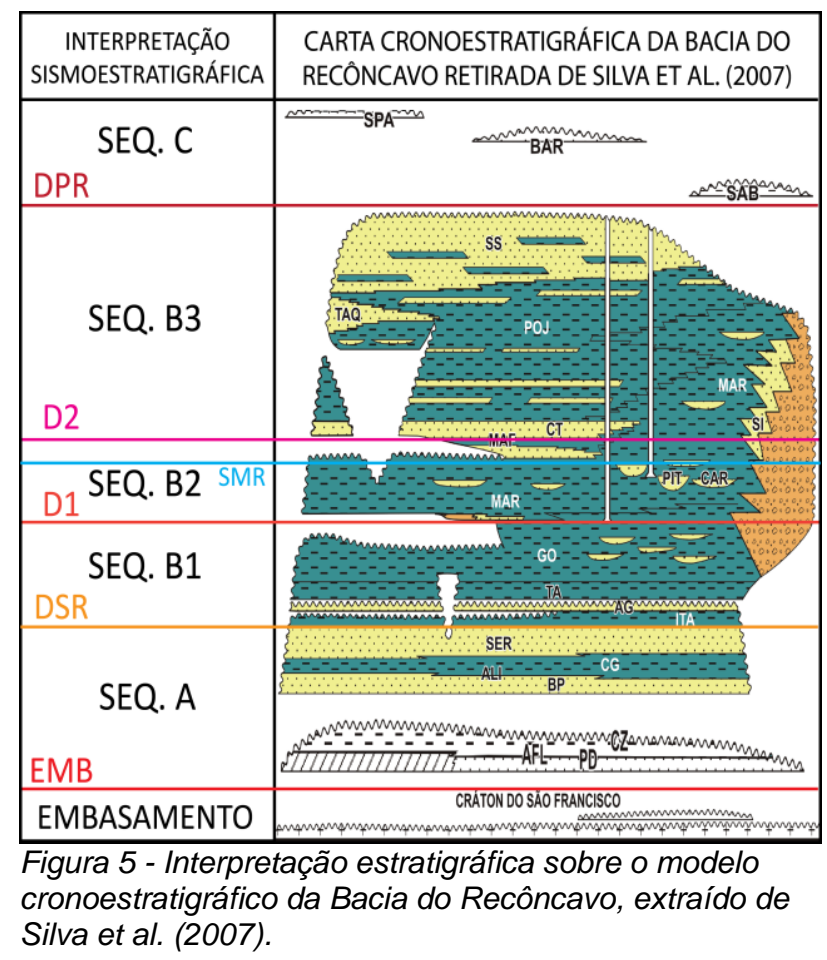

\section{Resultados}

O resultado da interpretação sísmica pode ser visualizado através das seções da Figura 6 , de uma linha sísmica que atravessa a Baía de Todos os Santos (Bahia), ilustrando, respectivamente, a seção empilhada não interpretada; a seção interpretada estratigraficamente; a seção com o atributo TecVA e sua interpretação estrutural; e o modelo interpretado. Com o intuito de correlacionar os depósitos entre as bacias analisadas, foi também confeccionada uma seção composta, apresentada na Figura 7, que liga a região da Baía de Todos os Santos (sobre a porção sul da Bacia do Recôncavo) com a área norte da Bacia de Camamu, seguindo uma direção predominante NW-SE. A seção 
composta apresenta trechos de linhas dips, e evidencia a continuação dos depósitos sin-rifte entre as seções.

Mapas de topos estruturais das principais superfícies estratigráficas demarcadas foram confeccionados e ilustrados na Figura 8. Eles indicam, basicamente, as profundidades às quais as superfícies se encontram atualmente, e o quanto variam na área de estudo. Podese inferir que os depocentros das bacias caminham em direção à Falha de Salvador e à porção sul da Bacia de Camamu, como mostram os mapas do embasamento e DSR (figuras 8a e 8b). Também é possível notar algumas mudanças nos depocentros ao longo da evolução da sedimentação, como mostra o deslocamento das regiões mais profundas entre as discordâncias DSR, D1, D2 e DPR (respectivamente, figuras $8 b, 8 c, 8 e$ e $8 f$ ). Tal evolução é marcada por uma diminuição das variações de profundidade ao longo das superfícies.

\section{Discussão e Conclusões}

A interpretação sísmica realizada, permitiu a identificação de discordâncias internas à seção rifte das bacias em estudo, e, portanto, a delimitação em pelo menos três sequências de terceira ordem na fase sin-rifte (vide Figura 6), o que evidencia o caráter episódico do tectonismo sofrido pelas bacias durante o período de rifteamento.

As bacias do Recôncavo e de Camamu apresentam correlação cronoestratigráfica em seus depósitos das fases sinéclise, pré-rifte e sin-rifte, como demonstrado no mapeamento das sequências A, B1, B2 e B3 (ilustrados na seção composta da Figura 7, e nos mapas da Figura 8). Portanto, o limite estrutural entre elas, que constitui o Sistema de Falhas da Barra, não limita, estratigraficamente, os depósitos da fase rifte entre as bacias. A diferença evidente entre as duas ocorre na fase pós-rifte (sequência $\mathrm{C}$ ) onde na Bacia do Recôncavo apresenta um caráter continental, com predominância de depósitos flúvio-deltaicos, resultando em padrões gerais progradacionais, com refletores de alta amplitude; enquanto que em Camamu, tal sequência assume grande influência de depósitos marinhos rasos, refletindo uma transição ao sistema de margem passiva instalada na Bacia de Camamu.

A análise dos atributos sísmicos, especialmente o TecVA, foi fundamental no mapeamento estrutural do topo do embasamento e das principais falhas nas seções sísmicas (vide Figura $6 \mathrm{c}$ ), principalmente na região do Sistema de Falhas da Barra.

A análise dos dados de poços foi fundamental na interpretação sismoestratigráfica, apresentando grande concordância com as superfícies marcadas nas seções sísmicas. Outra grande contribuição dos dados de poços veio com a aplicação da estratigrafia de sequências para bacias rifte, onde foi encontrado uma superfície de máximo rifteamento interna à Sequência B2 (marcada como uma superfície de downlap), ao qual segmentou a sequência nos Tratos Tectônicos de Desenvolvimento de Rifte (TTDR) e de Final de Rifte (TTFR).

Nas demais sequências da fase rifte, até o momento não foram interpretadas as superfícies de máximo rifteamento (SMR), em virtude de limitação na qualidade sísmica, ao qual levou à baixa confiabilidade em sua interpretação, tendo sido restrita a apenas algumas seções sísmicas e poços. Outra superfície relevante na estratigrafia de sequências para modelos de bacias rifte, constitui a Superfície de Início de Desenvolvimento de Rifte (SIDR), análogo à superfície de regressão máxima para modelos de margem passiva. Esta foi interpretada apenas na análise de poços, não sendo possível sua identificação na sismoestratigrafia por problema de resolução sísmica, considerando que na interpretação dos poços tal superfície se apresentava a no máximo cem metros acima das discordâncias, repercutindo em apenas um ou dois pares de refletores nas seções sísmicas.

Os mapas da Figura 8 permitem concluir que os depocentros caminham para sudeste (região sul da Bacia de Camamu e Falha de Salvador), onde, ao longo de sua evolução, apresentam algumas variações em suas posições na área de estudo. Um exemplo dessas variações se encontra na região norte da Bacia de Camamu, ao qual se ressalta cada vez mais um depocentro logo abaixo da ilha de Itaparica, e apresenta diferenças de profundidades ao longo do limite entre as bacias.

\section{Agradecimentos}

Os autores agradecem à GEOPARK pelo financiamento do projeto RECAMU, à FAPESB e CAPES por bolsas de Pós-Graduação em Geofísica da UFBA. M.H. agradece ao $\mathrm{CNPq}$ por bolsa de produtividade em pesquisa ( $\mathrm{PQ}$ 304657/15-8).

\section{Referências}

Destro, N., et al. "Release faults, associated structures, and their control on petroleum trends in the Recôncavo rift, northeast Brazil" AAPG Bulletin, v. 87, no. 7 (July 2003), pp. 1123-1144.

Ferreira, T. S., et al. "Controle do embasamento no rifteamento das bacias de Camamu e Almada", Boletim de Geociências da Petrobras 17 (2009): 69-88.

Holz, M.; Troccoli, E.B.; Prado, M. 2014. Sequence Stratigraphy of Continental Rift Basins II: An Example from the Brazilian Cretaceous Recôncavo Basin. In: Rocha; Pais; Kullberg \& Finney. (Org.). STRATI 2013. Springer International Publishing, 2014, p. 15-18.

Prosser, S. "Rift-related linked depositional systems and their seismic expression." Geological Society, London, Special Publications 71.1 (1993): 35-66.

Silva, O. B., et al. "Bacia do Recôncavo." Boletim de Geociências da PETROBRAS 15.2 (2007): 423-431. 


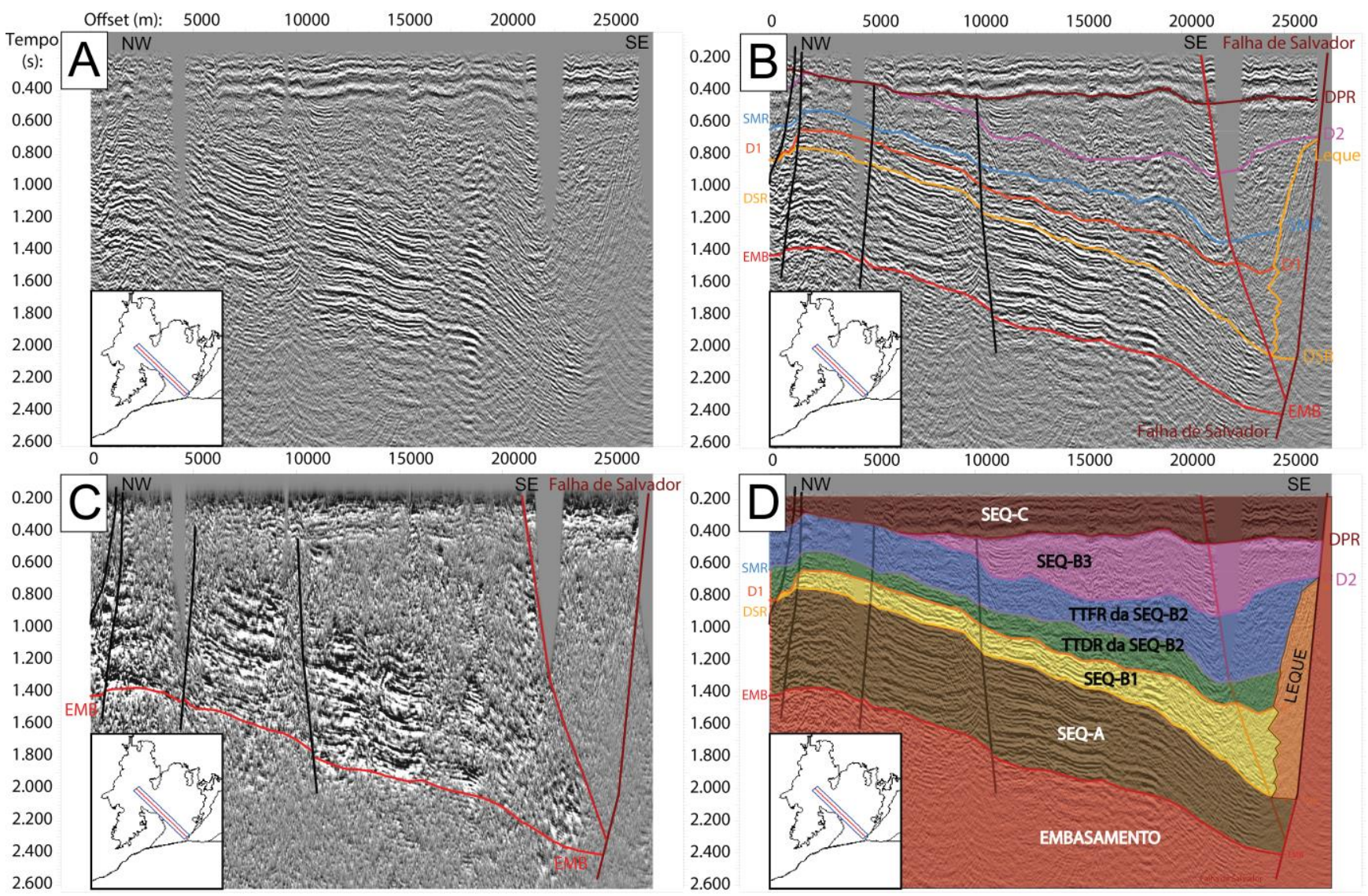

Figura 6 - Seção sísmica da região da Baía de Todos os Santos (área sul da Bacia do Recôncavo): (a) não interpretada; (b) interpretada; (c) com o atributo TecVA e interpretação estrutural; (d) sob o modelo estratigráfico interpretado.

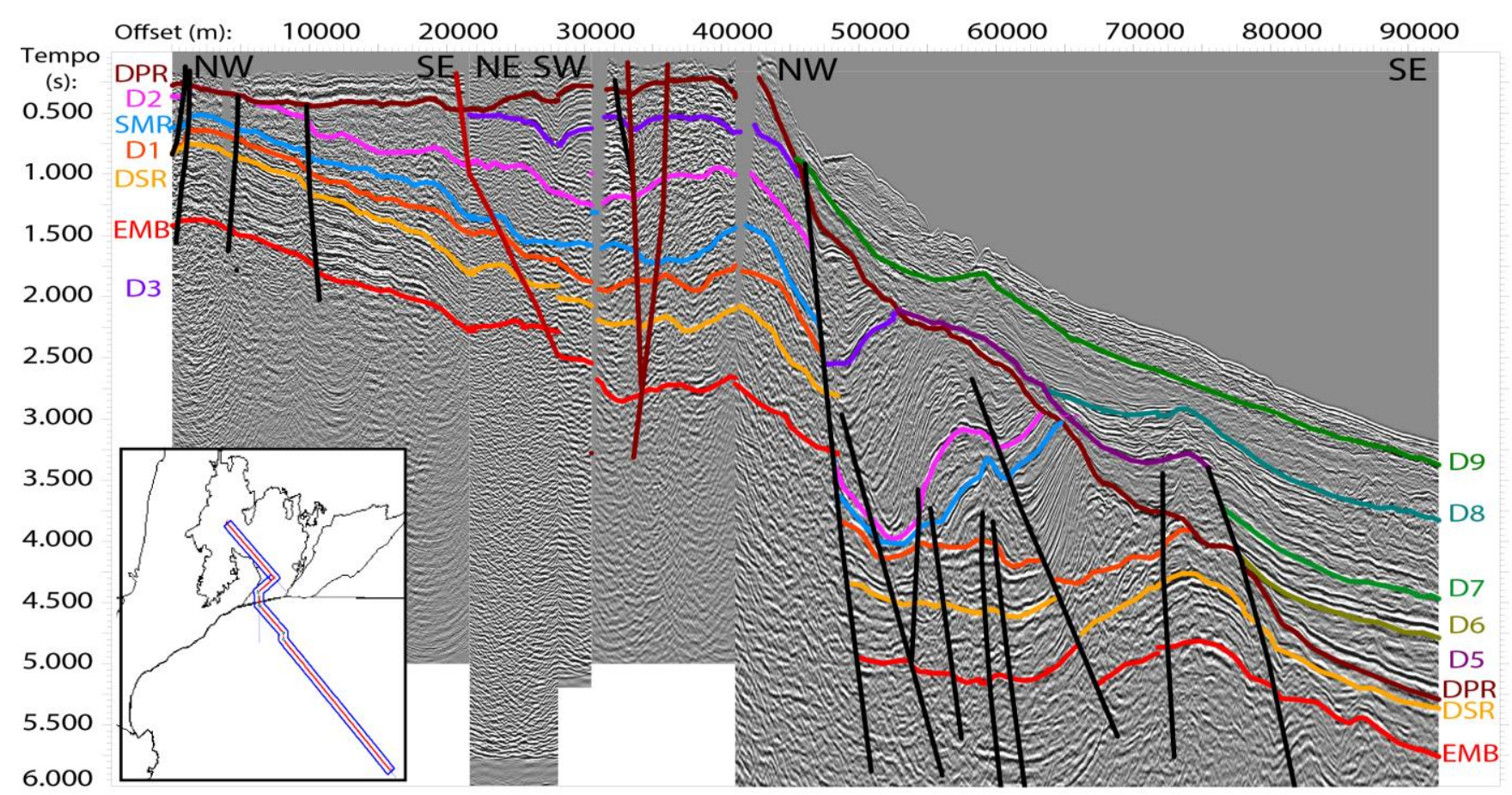

Figura 7 - Seção sísmica composta de direção preferencial NW-SE, correlacionando os depósitos sedimentares sob a região da Baía de Todos os Santos (sul da bacia do Recôncavo) e o norte da Bacia de Camamu. 

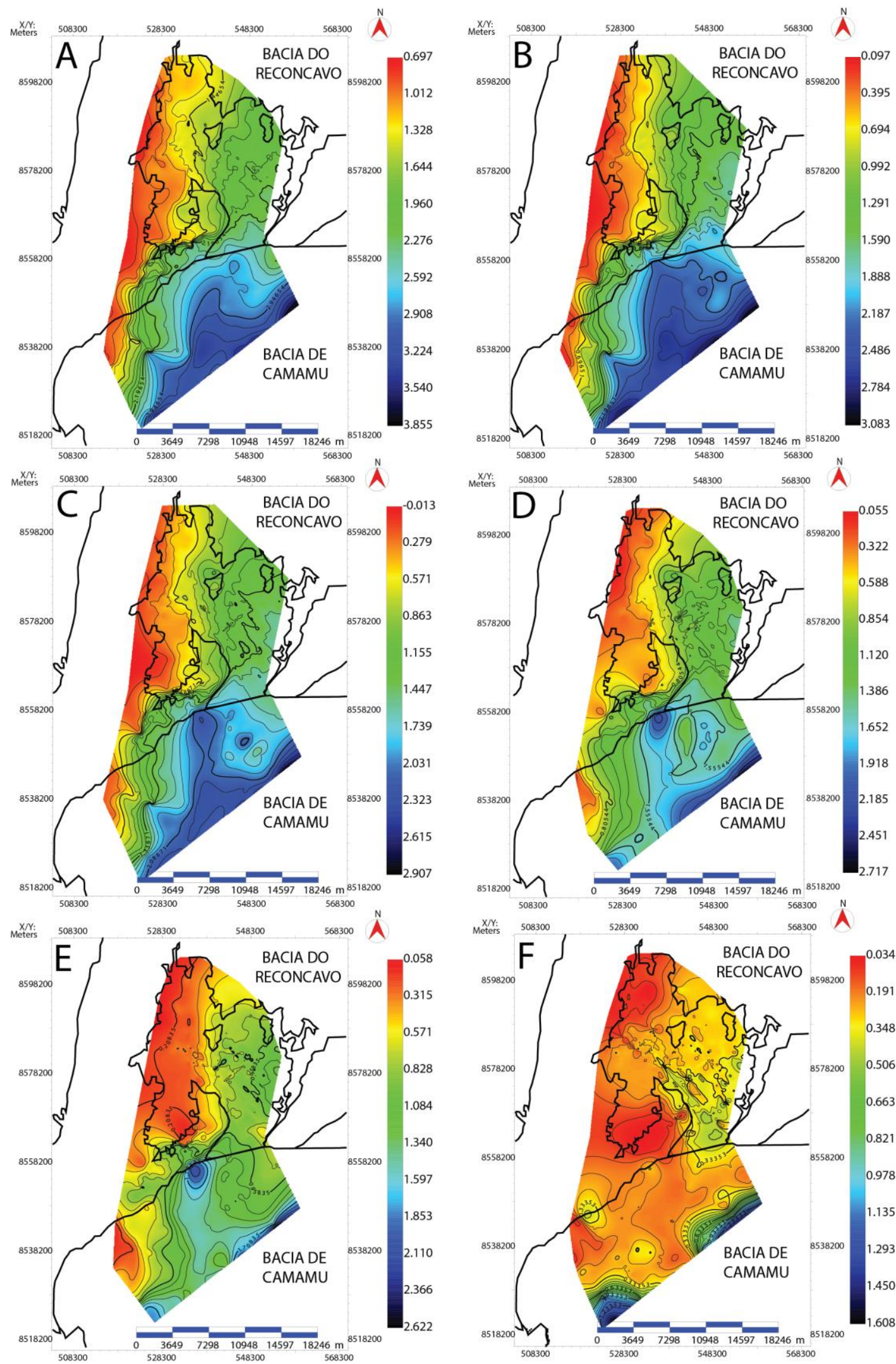

Figura 8 - Mapas de tempos sísmicos das superfícies estratigráficas interpretadas: (a) topo do embasamento; (b) discordância sin-rifte (DSR); (c) D1; (d) superfície de máximo rifteamento (SMR) da Sequência B2; (e) D2; (f) discordância pós-rifte (DPR). 